\section{Environmental and anthropogenic influences on the occurrence of iodine enrichment in groundwater at the North China Plain}

\author{
JUNXIA LI ${ }^{1}$, XIANJUN XIE ${ }^{2}$, XIAOBIN XUE ${ }^{1}$ AND \\ CHUNLI SU ${ }^{3}$ \\ ${ }^{1}$ China University of Geosciences, Wuhan \\ ${ }^{2}$ China University of Geosciences (Wuhan) \\ ${ }^{3}$ China University of Geoscience, Wuhan \\ Presenting Author: jxli@cug.edu.cn
}

Iodine nutrition has long been recognized as a key determinant in regulating thyroid hormones. The drinking water rich in natural geogenic iodine serves as one of important iodine sources, and it was estimated that almost 31 million people throughout 11 provinces in China are being exposed to excessive iodine uptake [1] (Fig. 1). At the North China Plain (NCP), which was one of the most densely populated coastal areas in the world, the iodine concentration can be up to $1106 \mu \mathrm{g} / \mathrm{L}$, and approximately $43 \%$ of groundwater iodine were higher than the guidelines for drinking water $(100 \mu \mathrm{g} / \mathrm{L})$. High iodine groundwater is mainly distributed in the Bohai bay area where serious land subsidence occurs. The accumulated land subsidence at the Cangzhou city from 1970 to 2013 was $2.68 \mathrm{~m}$ [2]. The results of compaction experiments showed that the pore solution compacted from the clayey sediments has a iodine concentration up to $830 \mathrm{mg} / \mathrm{L}$, indicating that the serious land subsidence resulted from the over-exploitation of groundwater serves as an important process causing the release of iodine into groundwater. The finding was further supported by the features of $\mathrm{Cl} / \mathrm{Br}$ molar ratio, ${ }^{87} \mathrm{Sr} /{ }^{86} \mathrm{Sr}$, and ${ }^{2} \mathrm{H}$ and ${ }^{18} \mathrm{O}$ of groundwater and pore water samples. Moreover, the groundwater environments at the coastal area characterized by $\mathrm{Na}-\mathrm{HCO}_{3} / \mathrm{Cl}$ type water, weak alkalinity and weak reducing conditions favor the iodine enrichment in groundwater. Iodide was the dominant species of groundwater iodine at the NCP. Reducing condition favors the mobilization and enrichment of groundwater iodide, which has the highest mobility among iodine species. Under the weak reducing/oxidizing conditions, as groundwater $\mathrm{pH}$ over the 'point of zero charge' of iron (oxy)hydroxides, the lowering adsorption capacity of groundwater iodide/iodate on minerals leads to the release of sediment iodine into groundwater.

References

[1] Shen, H.M., Liu, S.J., Sun, D.J., et al. Geographical distribution of drinking-water with high iodine level and association between high iodine level in drinking-water and goitre: a Chinese national investigation. Br J Nutr. 2011; 106(2): 243-7.

[2] Ye, S.J., Xue, Y.Q., Wu, J.C., et al. Progression and mitigation of land subsidence in China. Hydrol J. 2016, 24(3): 685-693.

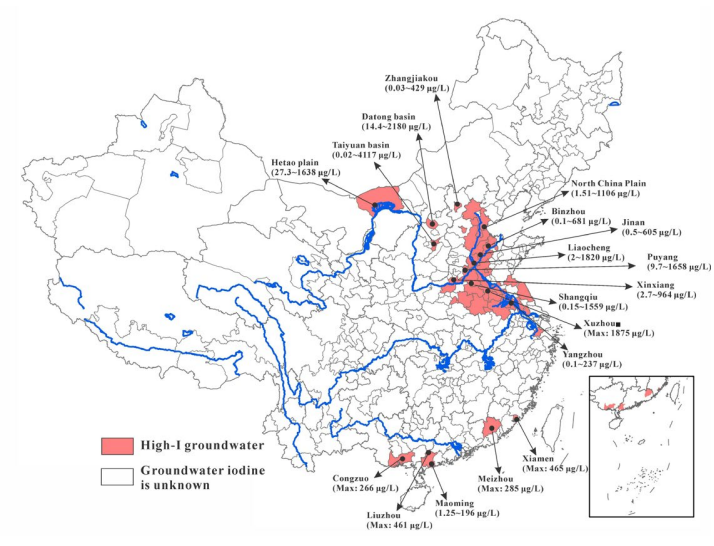

